\title{
PROPUESTA DE DIDACTIZACIÓN DE CONTENIDOS DE HISTORIA DE LA TRADUCCIÓN PARA LA FORMACIÓN DEL TRADUCTOR
}

\author{
Pilar Martino Alba \\ pilar.martino@urjc.es \\ Universidad Rey Juan Carlos
}

\section{Resumen}

La formación humanística inherente al traductor tiene uno de sus pilares en el conocimiento de la historia de la disciplina. En el proceso de enseñanza-aprendizaje, el futuro traductor tiene la oportunidad de ampliar su cosmovisión y aprender a manejar la lanzadera del telar de conocimiento enciclopédico que le permitirá tramar sus textos con artesanal y artística destreza, siendo éste uno de los objetivos de nuestra propuesta. Para ello, optamos por una didactización de contenidos, cuya metodología permita un aprendizaje constructivo en el que, en primer lugar, tras unas pinceladas presentadas a través de una selección de imágenes que hacen visible la actividad traductora, se propone una distribución cronológica por grandes periodos históricos, basándose en conocimientos culturales previos. En cada uno de dichos periodos, se analizan los contextos histórico-sociales y políticos a través de los textos; para adentrarse después en las biografías, sacando a la luz a los actores del proceso traductor; y, por último, se lleva a cabo el análisis, debate y comentario de los textos de los traductores, bien producto de la reflexión sobre su quehacer o bien de la reescritura y recepción de su obra. Así, pues, proponemos una visión circular y constructivista de la historia de la traducción que hace el recorrido mencionado por contexto, actor y texto tejiéndolos en un telar común, donde el hilo conductor de la historia de la traducción forma la trama del tapiz. 


\begin{abstract}
"A proposal for a course on the History of Translation for a humanistic translator training"

History of Translation should be considered a fundamental issue and one of the founding areas in the formative years of a translator. Within the teaching-learning process, the prospective translator has the opportunity to expand his/her worldview and learn how to handle the tapestry of encyclopedic knowledge which will allow weaving the texts with artistic skills and real craftsmanship. This constitutes the main objective of my proposal. The approach I take here extends beyond the introduction of chronological distribution divided into major historical periods. In each of them, I analyze the historical, sociological and political contexts based on texts and biographies which enable highlighting the real actors of the translation process. Finally, this approach leads toward the analysis and comments on the texts, those being the product of reflections on the translators' work. Thus, I propose a circular vision of the History of Translation, starting with a debate on the iconographic symbols which show clearly the translator's activity and, subsequently, drawing the circle mentioned previously, across the areas of context, actor and text.
\end{abstract}

Palabras clave: Historia de la traducción. Investigación histórica. Contexto. Traductor. Texto.

Keywords: History of Translation. Historical research. Context. Translator. Text.

Manuscript received on March 20, 2012 and accepted on September 6, 2012. 


\section{Introducción}

La propuesta hace unos años de impartir un curso de historia de la traducción en un posgrado de traducción, así como el reducido número de horas previamente asignado para ello, nos condujo a reflexionar sobre contenidos y su didactización, con el fin de que los estudiantes pudiesen extraer el mayor provecho posible de una asignatura fundamental para su formación humanística - aunque en los planes de estudio no siempre todo lo bien considerada que se merece, fuere cual fuere la especialidad elegida en el futuro para ejercer su actividad profesional- La reflexión nos llevó a organizar un proyecto que, a manera de torre de Babel, fuese ascendiendo escalonadamente desde la base de lo culturalmente conocido pasando por el debate y el fomento de la "tormenta de ideas", hasta llegar a nuevas perspectivas y propuestas de reflexión sobre la actividad traductora a lo largo de la historia por parte de los estudiantes, una vez adquiridos nuevos conocimientos con el desarrollo de los diferentes temas, pretendiendo con ello incentivar la curiosidad y la investigación sobre diferentes aspectos de la historia de la traducción.

El alto número y variada procedencia geográfica y cultural de los alumnos, además de su diversa especialización académica de grado, muchos de ellos sin un bagaje filológico y traductológico, aunque con un afán común por la lectura, ofrecía, a priori, la posibilidad de poner en común propuestas desde muy diferentes perspectivas, en función de la formación previa y de la particular cosmovisión según el ángulo del mundo donde cada uno de ellos se hubiese formado. Con tales premisas, nos planteamos una propuesta de didactización de contenidos de historia de la traducción para la formación del traductor que tuviese el suficiente atractivo como para interesar a un público tan heterogéneo y babélico, si bien con el objetivo común de formarse como traductores. Un reto, no cabe duda, pero salvable por el convencimiento absoluto de la idoneidad de una asignatura de historia de la traducción para la formación humanística del traductor. Este aspecto lo han tratado reconocidos historiadores de la traducción, como Vega (1994: 13-57; 1996-1997a: 71-85), Delisle (1995, trad. 2005; 2003: 221-235), Santoyo (1999) y otros. Incluso los dos primeros (Vega 2002-2003: 63; Delisle 2003: 227) sacan los colores 
a reputados traductólogos contemporáneos, como Mounin, quien, por desconocimiento de la historia de la traducción, yerra en la periodización de las teorías traductológicas.

Hacemos la advertencia de que al tratarse de un curso de historia de la traducción en un posgrado que se imparte en España, y en el que la palabra vertida es de seis lenguas extranjeras al español, se hace hincapié en el papel cultural desempeñado por España en la historia de dicha disciplina, si bien se abarcan, como por otro lado es lógico dada su importancia histórica, otros ámbitos geográficos. Lo contrario sería desvirtuar la historia de una actividad humana tan antigua como la presencia del hombre en la tierra. Además de ello, en el proyecto de didactización de contenidos se ha pretendido, por qué no decirlo, compensar las escasas referencias bibliográficas que, por regla general, los historiadores de la traducción del mundo anglófono, germano o bien francófono hacen a la labor realizada por grandes eruditos hispanos, traductores y teóricos de la traducción a lo largo de la historia de la disciplina; y también de transmitir a los jóvenes, futuros profesionales de la traducción, el valor de las investigaciones realizadas en el campo de historia de la traducción por autores españoles, como la encomiable labor de Menéndez Pelayo, modelo para muchos hasta nuestros días en que se cumplen los cien años de su fallecimiento.

\section{Primer escalón: Imágenes que hacen visible la actividad traductora}

Ante la pregunta ¿por qué proyectar imágenes como primer paso para hablar de la historia de la disciplina?, uno encuentra múltiples razones, no siendo baladí el innegable atractivo de contemplar la historia a través del arte, como bien puso de manifiesto García de Cortázar (2007: VIII), siguiendo el consejo de Voltaire, de quien dice que para él el secreto de no aburrir consistía en no contarlo todo, ya que ello permite ofrecer el contenido a manera de sugeridoras pinceladas.

Otra de las razones que nos parece fundamental para iniciar de modo gráfico un curso de historia de la traducción reside en la enorme influencia del actual entorno mediático y tecnológico para percibir el mundo y sus circunstancias, donde parece que hay que 'ver', antes que 'leer' para 'captar' aquello que se nos quiere transmitir. En tercer lugar, se trata de comprobar hasta qué punto sabemos 'qué vemos' pero no lo que vemos en toda su dimensión significativa y de hito histórico para la historia social, cultural y de la traducción. Teniendo en cuenta el número de créditos asignados a la historia de la traducción en los planes de estudio, nos parece que es un buen modo de introducir 
a los discentes en una disciplina cuyo contenido abarca, cronológicamente hablando, varios milenios.

Dada la limitación de espacio, hemos hecho una selección de veinte imágenes, de las que la primera decena pretende despertar el poso cognitivo semidormido en la caja negra del estudiante y futuro traductor. Ante ellas, la primera palabra la tienen los discentes, a quienes se les pide que, a manera de tormenta de ideas, verbalicen ideas y conceptos asociados a la imagen proyectada. Refrescar el significado de esas diez imágenes tiene como objetivo fijar conocimientos y ampliar la visión humanística del estudiante.

La segunda decena de imágenes, a manera de pinceladas, tiene por objetivo despertar la conciencia sobre la importancia de la historia de la traducción, sus avatares, la relevancia del traductor como puente lingüístico-cultural, las funciones que ha desarrollado y desarrolla en la historia de la cultura, la historia de la traducción escrita y oral, y la investigación en historia de la traducción.

A continuación relacionamos una veintena de imágenes, para pasar a describir posteriormente algunas de las ideas y cuestiones asociadas a las mismas por parte tanto del docente como del discente.

\subsection{Selección de veinte diapositivas a proyectar:}

1. Torre de Babel, grabado de Gustave Doré (1833-1883), en The Doré Gallery of Bible Illustrations, Chicago, 1891.

2. Tablilla sumeria, escritura cuneiforme (ca. 2100 a. C.) y Código de Hammurabi (1760 a. C.), Museo Pergamon, Berlín.

3. Piedra Rosetta (196 c.C.), Museo Británico, Londres, y escultura del Escriba sentado (ca. 2400 a.C.), Museo del Louvre, París.

4. Bustos de Herodoto ( 480 - 425 a.C.), de Aristóteles (384 - 322 a.C.) y de Cicerón (106 - 43 a.C.)

5. Monumentos al médico y filósofo Averroes (1126 - 1198) y al filósofo Maimónides (1135 - 1204), en Córdoba.

6. Miniatura de Alfonso X El Sabio, acompañado de un escriba. Libro de los juegos. Biblioteca del Monasterio de San Lorenzo de El Escorial (Madrid).

7. Busto de Étienne Dolet (1509-1546), en los jardines del ayuntamiento de Orléans, Francia.

8. Miniatura de San Jerónimo en su estudio, en Postillae perpetuae in universam S. Scripturam, de Nicolás de Lyra (1270-1340), Biblioteca del convento S. Antonio de Padua, Barcelona. 
9. Fresco de San Jerónimo dictando a sus monjes, Monasterio de San Isidoro del Campo, Itálica (Sevilla).

10. Monumento a Johannes Gutenberg (ca.1399-1468), en Maguncia, Alemania.

11. Página de la Biblia Políglota Complutense (1502-1517), promovida por el Cardenal Cisneros.

12. Selección de dibujos de la edición de El Quijote, ilustrada por Antonio Mingote, Madrid: Ed. Planeta, 2005 [Edición revisada, introducción y notas de Martín de Riquer].

13. Página de los vocabularios de lenguas amerindias encargados a Celestino Mutis por orden de Carlos III, a petición de Catalina de Rusia; Real Biblioteca, Palacio Real de Madrid.

14. Portada del Índice de los Libros prohibidos, Madrid, 1873.

15. Monumento a don Marcelino Menéndez Pelayo (1856-1912), de Mariano Benlliure, en la Casa y Biblioteca Menéndez Pelayo, Santander.

16. Fotografía de la biblioteca Aurelio Espinosa Pólit (1894-1961), en Quito, Ecuador.

17. Fotogramas de las películas El juicio de Nuremberg (1961), La niña de tus ojos (1998), Lost in Translation (2003), Spanglish (2004), La intérprete (2005).

18. Retrato de Xingjian Gao, primer Premio Nobel chino.

19. Página de la Biblioteca Virtual Miguel de Cervantes www.cervantesvirtual.com

20. Página del grupo de investigación HISTRAD

El trabajo a realizar con las imágenes proyectadas se organiza del siguiente modo: en cada una de ellas se plantean tres preguntas, a saber, qué ve el estudiante, qué sabe sobre lo que está viendo y qué le sugiere. En el caso de uno de los iconos más reconocibles como símbolo iconográfico de la actividad traductora, la torre de Babel (diapositiva 1), prácticamente la totalidad del grupo, sea cual fuere su procedencia geográfica, identifica el objeto, pero pocos o ninguno se atreven a fijar cronológicamente el hecho narrado en el texto bíblico o situar en cuál de los libros del Antiguo Testamento (Génesis $11,1-9$ ) aparece la historia y qué es concretamente lo que se narra. Ello da pie al docente para una explicación sobre el hecho y su significado, tras lo cual se propone la realización de tareas, tales como:

- Adquirir un ejemplar del suplemento cultural Babelia y localizar una crítica de traducción. 
- Consultar un número de la antigua revista de arte y cultura Babel, que está digitalizada y accesible en Internet, y localizar el nombre de al menos dos traductores.

- Buscar datos biográficos sobre George Steiner y la razón de que titulase una de sus obras Después de Babel.

- Localizar datos biográficos sobre Gustave Doré, autor del grabado que se proyecta, y averiguar qué otras obras de la literatura universal ilustró, poniendo en práctica la interpretación de un texto escrito mediante un lenguaje diferente al del texto original.

En la diapositiva número 4, en la que se proyectan los bustos de Herodoto, Aristóteles y Cicerón, el retrato más fácilmente identificable por parte de los estudiantes, o quizá se trate del primer nombre de erudito de la Antigüedad que el cerebro es capaz de extraer de su disco duro y traerlo al presente, es Aristóteles. Sea cual fuere la razón de haber reconocido al gran pensador griego, la duda surge ante la pregunta de ¿qué profesión tuvo? La respuesta mayoritaria se queda en 'filósofo'. En este punto es necesario incidir en la aristotélica perspectiva abarcadora, ya que Aristóteles, a modo de un Leonardo de la Antigüedad, escribió sobre matemáticas, geografía, física, zoología, ética, política, filosofía, etc. El fijar la figura del pensador y su obra es necesario, porque servirá de base para comprender la fascinación y éxito que sus obras científicas tuvieron para las escuelas de traductores de Bagdad, Córdoba y Toledo.

Tras las pinceladas biográficas de los clásicos, se plantean las tareas que servirán para fijar conocimientos y relacionarlos con la historia de la traducción.

- Buscar respuesta a las siguientes preguntas sobre Herodoto, magnífico ejemplo de homo viator, homo scribens: ¿Qué significó el siglo $\mathrm{V}$ a. de C. para Atenas desde el punto de vista político y del mecenazgo cultual? ¿Cuáles fueron los motivos de los múltiples viajes del historiador Herodoto? ¿Qué relación puede tener la sed de conocimientos de Herodoto con la formación humanística del traductor?

- Por lo que respecta a Aristóteles: ¿Qué institución fue la Escuela de Atenas? Durante el Renacimiento se vuelven los ojos a la Antigüedad clásica, de manera que se les pide a los estudiantes que localicen la representación iconográfica de dicha institución del mundo clásico entre las obras de los pintores renacentistas.

- Y, en relación con Cicerón, ¿qué obras escribió y por qué El orador se considera un texto fundamental y de lectura muy recomendable para un traductor literario? 
- Consultar los estudios introductorios de las siguientes traducciones: Herodoto: Historia, traducido por José M. Floristán (2010); Fuhrmann, Manfred: La teoría poética de la Antigüedad. Aristóteles-Horacio-Longino, traducido por Alfonso Silván (2011); y, en el caso de El orador, de Cicerón, la introducción del traductor Eustaquio Sánchez Salor (2008).

Basándonos en este primer escalón, en el quinto epígrafe de nuestro artículo uno de los textos a analizar, debatir y comentar será un fragmento de El orador perfecto, de Cicerón (en Vega 1994: 77).

Pongamos ahora por caso la diapositiva 9, los frescos de la vida de san Jerónimo (ca. 347 - 420) en el monasterio de San Isidoro del Campo, una de cuyas escenas presenta al que en Occidente se considera patrón de los traductores y en cuya onomástica se celebra el Día Internacional del Traductor. La razón de escoger esta imagen y no una en las que el santo es fácilmente reconocible, bien porque vista ropaje cardenalicio o bien porque aparezca en el desierto de Calcis, en calidad de penitente, traduciendo los textos bíblicos, es para que sirva de apoyo para completar las pinceladas biográficas sobre el personaje, iniciadas en la proyección de la diapositiva 8. En esta imagen aparece con hábito monacal, rodeado de monjes a los que está dictando, momento en el que se abre una puerta por la que aparece un personaje ajeno al monasterio. Se trata de la escena que relata el momento en que recibe en Belén una carta de alguno de sus múltiples corresponsales, momento en el que se hace alusión a la epístola a Panmaquio sobre el arte de bien traducir. Y la razón de escoger una escena del antiguo monasterio jerónimo en tierras hispalenses es porque de él salieron dos monjes jerónimos que se adhirieron a la Reforma, Cipriano Valera (1532 - 1602) y Casiodoro de Reina (1520 - 1594). Ello da pie también para tratar la traducción y revisión de la llamada Biblia del Oso, y de la vida del traductor en el siglo XVI, para quien el ejercicio de la actividad traductora llegó a ser en ocasiones profesión de riesgo; aspecto éste del que se trata ampliamente con la proyección de la diapositiva 7 , es decir la del busto del traductor y humanista francés Étienne Dolet, quemado en la hoguera tras ser declarado hereje, mientras que en la número 8, que representa a san Jerónimo en su estudio en una miniatura de la llamada Biblia de Nicolás de Lyra, se plantean las antiguas versiones bíblicas, basándonos en varios artículos de Jesús Cantera (1995: 53-60; 1997: 101-117; 1999: 107-124) que los alumnos deben leer previamente, con el fin de que se abra el intercambio de opiniones.

Las tareas a realizar relacionadas con la escena de san Jerónimo dictando a sus monjes, deben responder a las siguientes preguntas: 
- Averiguar cuándo declaró la UNESCO el 30 de septiembre Día internacional del traductor.

- Buscar datos sobre cuándo se empiezan a traducir los textos bíblicos a las lenguas vulgares, basándonos en los citados artículos de Cantera previamente distribuidos.

- Como intercambio de ideas en equipo, teniendo en cuenta la diversa procedencia geográfica del grupo, tal y como hemos mencionado al inicio, cuestionarse si existe en las culturas orientales un personaje al que se considere icono de la traducción como es el caso de san Jerónimo para Occidente. En caso afirmativo, ¿quién y por qué?

Hasta aquí hemos visto tan sólo tres ejemplos de la primera decena de imágenes proyectadas. Tal como decíamos más arriba, con la segunda decena se trata de ir haciendo incursiones en otros aspectos menos reconocibles para el estudiante de posgrado, especialmente para aquel que no proceda de los estudios de Grado en Traducción. Tal sería el caso, por ejemplo, de la diapositiva 12 (la ilustración del Quijote), que sirve como base para hablar de la diferente interpretación del texto por parte de los traductores, así como de ejemplos de traducción intersemiótica a lo largo de la historia de la disciplina. En este punto, y como método de asentamiento de conocimientos, se pone en relación con la ilustración de la Biblia por Gustave Doré, vista con anterioridad.

La diapositiva 13 da pie para abordar la importante labor de los misioneros en la elaboración de Artes y vocabularios y del papel del traductor en diferentes campos del saber, entre ellos el de la lexicografía. Se remite al estudiante a un artículo de Van Hoof (1996-1997: 17-26), en francés, y al capítulo 8 del libro de Delisle sobre Los traductores en la historia (2005: 191-202), donde el texto de Van Hoof sobre los traductores como autores de diccionarios está traducido al español.

La número 14 muestra el Índice de libros prohibidos. La proyección de esta imagen abre el debate sobre el interesante tema de la censura de obras y las consecuencias que ello ha tenido a lo largo de la historia de la traducción, así como las estrategias de editores y traductores para escapar al ojo censor. En este punto se hace una incursión en el proceso de revisión y edición de obras traducidas, y se presentan a debate casos concretos de procesos censores. Uno de los casos versa sobre un proceso censor tras la promulgación de la Pragmática de Felipe II, publicada en 1558, titulada La Orden que se ha tener en imprimir los libros; y el segundo aborda la censura de las obras del autor literario y traductor ruso Boris Pasternak o la censura de libros en la Alemania nazi de los años treinta del siglo pasado, como un modo de mostrar que los 
procesos de carácter inquisitorial hacia la cultura se han dado a lo largo de la historia en todo el orbe.

La proyección de la diapositiva número 17 conforma la base para ofrecer unas pinceladas sobre la historia de los intérpretes y su papel en el devenir de la Humanidad, haciendo hincapié en que las relaciones comerciales y políticas han contado con estos mediadores lingüísticos desde tiempos inmemoriales.

Estos toques cromáticos sobre la interpretación y traducción como acto fundamental de comunicación se amplían posteriormente, en el escalón en el que los estudiantes leerán un artículo sobre el tema (Vega 2004: 81-108).

Las últimas imágenes que se proyectan constituyen una muestra de los resultados de la investigación en historia de la traducción desde muy diferentes ángulos y pretenden estimular la curiosidad de los estudiantes por adentrarse en los recovecos de la historia. Uno de los ejemplos, la diapositiva 20, muestra el perfil y razón de ser del grupo de investigación HISTRAD, dirigido por el profesor Miguel Ángel Vega Cernuda, cuyos objetivos se centran en la investigación en historia de la traducción en España e Hispanoamérica. El revisar con los estudiantes la documentación disponible, ya se trate de perfiles biográficos de traductores o bien artículos sobre recepción o historia de la traducción, contribuye a fomentar el interés por la disciplina, pero también ayuda a que valoren la labor investigadora de los docentes.

\section{Segundo escalón: Distribución cronológica por grandes periodos históricos y sus contextos}

Tras este primer lienzo de la historia de la traducción presentado en el epígrafe anterior a modo de collage, que es únicamente un esbozo de lo que será la obra terminada, apostamos por una distribución cronológica por grandes periodos históricos, si bien también se puede optar por una clasificación por ámbitos geográficos o, tal y como propone Ruiz Casanova (2000: 12), por la división cronológica basada en la literatura, teniendo en cuenta que "[...] la traducción es un hecho literario más de una lengua. Como operación consistente en trasladar un texto, la traducción participa del conocimiento histórico de las lenguas y las literaturas a las que se aplica [...]". De lo que se trata, al fin y al cabo, es de tener un punto de apoyo para contextualizar biográficamente a los traductores, su actividad traductora, la reflexión sobre la misma, así como la recepción de sus obras, con el fin de poder relacionar diferentes hechos, ya sean históricos, literarios, políticos, etc. con la traducción. Así, por ejemplo, Delisle (1995, cfr. trad. 2005) hace un original planteamiento que se aleja de una cronología histórica o literaria y plantea la historia de la traducción dividida por la actividad de sus protagonistas, los traductores, fijando la 
atención en su contribución a la historia de la cultura. Así, pues, divide los capítulos en 'Los traductores, inventores de alfabetos', 'forjadores de lenguas nacionales', 'artesanos de literaturas nacionales', 'difusores del conocimiento', 'actores en la escena del poder', 'propagadores de religiones', 'importadores de valores culturales', 'redactores de diccionarios' y, por último, 'Los intérpretes, testigos privilegiados de la historia'.

Nuestro planteamiento es, sobre todo, didáctico y teniendo en cuenta qué tipo de público es el destinatario de la disciplina de historia de la traducción, la elección de una división inicial por grandes periodos históricos se debe a las lagunas culturales con las que, lamentablemente, llega gran parte del estudiantado y porque creemos sinceramente que esta división sirve mejor como anclaje para explicar posteriormente contextos, traductores y textos.

Como ya hemos mencionado, sea cual fuere el criterio elegido para enmarcar el objeto de estudio, lo fundamental es tener puntos de apoyo que nos ayuden a relacionar unos hechos con otros, especialmente porque desarrollar la capacidad de relación contribuye a ampliar la cosmovisión, los horizontes mentales y, consecuentemente, a mejorar nuestra formación humanística como traductores. Teniendo presente el breve recorrido, explicado en el epígrafe anterior, por algunos hechos de la historia de la traducción a través de las imágenes y las tareas planteadas a los estudiantes para localizar determinados datos, sabemos por experiencia que el apoyo histórico les ayuda a contextualizar hechos. De manera que el optar por establecer una tabla, en la que los parámetros sean 'grandes periodos históricos' según la división tradicional, permite a un amplio número de estudiantes situarse con mayor confianza sobre lo ya conocido; y al docente se le facilita el proyecto de poner en marcha el aprendizaje constructivista. Una vez hecha la división en tan sólo cuatro grandes apartados, aunque subdivididos según se relaciona a continuación:

a. la Antigüedad, subdividida en las culturas de Oriente y en la Antigüedad clásica;

b. la Edad Media, subdividida en la alta y en la baja Edad Media, y cada una de ellas en Oriente y Occidente.

c. la Edad Moderna, subdividida en los siglos XV y XVI, por un lado, y en los siglos XVII y XVIII, por otro; y, por último,

d. la Edad Contemporánea, subdividida en los siglos XIX, por un lado, y XX-XXI, por otro.

El siguiente paso consiste en ofrecer un pequeño corpus de textos, en los que sean claras las referencias al contexto histórico-social, histórico-político, histórico-literario, histórico-económico, histórico-científico, etc. en que se ha 
desarrollado la traducción; de manera que en un marco temporal concreto se estudie uno o varios contextos en los que los traductores han reescrito o elaborado sus textos. En este artículo, dada la limitación de espacio de este tipo de contribuciones, nos centramos en poner un ejemplo de texto dentro de alguno de esos contextos mencionados.

\subsection{Contexto histórico-político a través de los traductores y los textos.}

El texto que aquí traemos a colación (AGI, sección Estado, sig. 61N36, Archivo General de Indias) es una instancia dirigida al gobernador de la provincia de Maracaibo, el capitán general de ingenieros, el ciudadano Vasseur, firmada en dicha población a 18 de junio de 1803 por el Provincial de la Orden de San Francisco, Fr. Francisco Javier Cuvillán. En dicha instancia solicita que las alhajas y ornamentos que están en el convento franciscano de Santo Domingo se trasladen a otros conventos de la Orden, al haber quedado el citado convento ocupado por los franceses y destinado a hospital militar. El texto original escrito por el P. Cuvillán, con la relación de alhajas y ornamentos, está en francés. La traducción al español, obra de Fr. José Marín Romano, termina con un párrafo en el que se certifica que lo traducido se corresponde con el documento original.

Certifico que la presente es traducción fiel y legalmente hecha de los documentos franceses que para el efecto me pasó N.M.R.P. Mtro. Provãl. Fr. Francisco Xavier Cuvillan con cuyo orn. la he verificado y para que conste lo firmo en Maracaybo a 13. de Agosto de 1803. (firma) Josef Martín Román

A la vista de este documento, surgen varias preguntas. Por un lado, la fecha puede parecer temprana, ya que la guerra de independencia de Venezuela se libra entre 1810 y 1823, pero ya desde 1797 habían comenzado los procesos revolucionarios que desembocaron en la guerra. Por otro, quizá llame la atención que los religiosos fuesen autores y traductores de estos documentos administrativos, pero los ejemplos de traducción administrativa en las órdenes religiosas son múltiples, ya que el contacto directo con las autoridades producía una correspondencia que no siempre era en español. A título de ejemplo, en los conventos se traducían sistemáticamente todas las bulas, y recordemos que las bulas no siempre aluden a asuntos meramente religiosos, aunque el emisor sea una institución religiosa. Además de ello, éste es un documento con un lenguaje especializado que quizá un traductor no religioso no hubiese podido resolver con soltura. La relación de alhajas y ornamentos que figura en el documento es como sigue:

[...] una custodia de plata sobredorada, un cáliz con su patena de planta sobredorada, una caldereta y su hisopo de plata, un incensario de plata con su 
naveta y su cucharita, tres pares de vinagreras con sus platicos y una campanita de plata, un resplandor de plata montada sobre hierro que tiene quarenta y tres planchas, quince casullas completas, dos estolas, quatro dalmáticas completas, tres capas, ocho alvas, siete sobrepellices, una caja de corporales y purificadores, nueve frontales de tafetán carmesí [...].

A partir de las guerras de Independencia en Hispanoamérica crece en progresión geométrica el interés por la traducción de textos franceses, de manera que en el estudio de la recepción de obras francesas en aquellos países o de las biografías de los traductores que abordan el traslado de estos textos, tendremos que tener en cuenta el entorno político favorable para la proliferación de traducciones del y al francés. A este lado del Atlántico, el estudio de un contexto histórico-político en relación con la traducción se puede abordar desde la perspectiva de la situación en diversas cortes europeas (Fernández Sánchez y Sabio Pinilla 1999: 72), desde el punto de vista de las relaciones internacionales (De Bernardo et al. 2011), desde el ángulo de la traducción en periodos de situación bélica, etc.

\subsection{Contexto histórico-literario a través de los traductores y los textos.}

Para ilustrar un contexto histórico-literario concreto, hemos acudido a la obra de Pajares Infante (2010) sobre la novela inglesa del siglo XVIII y su fortuna editorial tanto en la propia Inglaterra como en otros países, debido a que el público destinatario era, sobre todo, la clase media:

[...] los datos históricos que se conocen revelan un incremento importante en el número de lectores y que las famosas circulating libraries, en las que por una módica cantidad de dinero se podía alquilar un libro, tuvieron gran éxito [...] evolución y desarrollo de la novela inglesa, la gran variedad de subgéneros y su importancia cualitativa y cuantitativa. Despreciada, en un principio, como entretenimiento vano que no aportaba nada útil, no transcurrieron muchos años hasta que fuese precisamente este género de ficción el más demandado por los lectores europeos [...] fueron precisamente críticos, autores y traductores franceses los que dieron a conocer la novela inglesa en todo el Continente y que los Prévost, Voltaire, Rousseau, Le Tourneur, Diderot... fueron los grandes valedores de los novelistas ingleses del XVIII y quienes mejor supieron apreciarlos. (Pajares Infante 2010: 4-16)

Tras una relación de obras de autores del XVIII, tales como Jonathan Swift, Daniel Defoe, Samuel Richardson, Henry Fielding, Laurence Sterne, Walter Scott, Tobias Smollett, Oliver Goldsmith, Robert Bage, William Goldwin, Horace Walpole, Mathew Lewis, Anne Radcliffe, Jane Austen, y de otros autores del XIX como Mary Shelley, las hermanas Brönte, Henry James y un largo etcétera, cabe preguntarse qué se tradujo de toda esa abundante producción 
literaria en lengua inglesa. A esta cuestión deben responder los discentes con un trabajo en equipo, basado en las consultas bibliográficas por parte de los alumnos cuyas lenguas de trabajo sean inglés-español, mientras que, por ejemplo, para los que trabajan con el par de lenguas francés-español u otras se les orienta hacia las búsquedas bibliográficas en las obras completas de Juretschke: España y Europa. Estudios de crítica cultural (2001) o bien hacia Lafarga, Palacios y Saura (2002).

Un interesante ejemplo de la labor de difusión de obras extranjeras realizada por un traductor en un contexto histórico-literario concreto, el de la Italia de la primera mitad del XX, nos los ofrece María Luisa Tobar (2012: 112-113) a propósito del autor literario y traductor Elio Vittorini, quien, no cabe duda, contribuyó a ampliar el canon literario en el polisistema literario italiano.

[...] su labor de traductor juega un papel importantísimo dentro de un proyecto cultural que tiene como objetivo introducir y hacer conocer en Italia la literatura extranjera para favorecer el proceso de renovación y modernización de la cultura y de la literatura italiana. La fascinación que ejerció Vittorini sobre los jóvenes en los años cuarenta y cincuenta se debe, más que a su obra de escritor, a su empeño constante en el ámbito cultural, tanto en el proceso de producción como de difusión [...] Traductor vivaz y original, Vittorini tiene el mérito de haber despertado el interés italiano por la literatura y la cultura americanas $[\ldots]$

\subsection{Contexto histórico-social a través de los traductores y los textos}

El ejemplo que hemos tomado para analizar un contexto histórico-social concreto a través del cual se pueda estudiar la labor realizada por los traductores en ese cronotopo está basado en un artículo de Lourdes Arencibia (19961997: 27-40), en el que la autora aborda el destacado papel desempeñado por las tertulias literarias en la Cuba del siglo XIX para que proliferase el interés por las obras literarias extranjeras y, consecuentemente, por la traducción de las mismas. Gracias al impagable mecenazgo de personajes como Domingo del Monte (1804-1853), quien seleccionaba y adquiría obras literarias extranjeras, que, una vez traducidas, se encargaba él mismo de revisar, imprimir y editar. Esas traducciones, una vez realizadas, circulaban en las tertulias, se comentaban y juzgaban. Un ejemplo de la traducción que encargara Domingo del Monte del Tratado de Legislación, de Charles Comte, es el siguiente texto que comenta dicho trabajo traductivo:

La traducción de Comte está ya para concluirse, y en lo que más demora es en la copia de los borradores; ayer he convenido con Valle que le encargue a Osés que aclare un poco la letra y que empecemos a remitir materiales al 
Norte, pues en teniendo allí persona inteligente que se haga cargo de corregir las pruebas se pueden evitar equivocaciones materiales en algunas letras, y aprovechar mucho tiempo [...] trabaja mucho en la traducción de Comte la cual con la ayuda del alemancito Osés pronto saldrá a la luz pública. (Del Monte 1834, cit en Del Monte 1822-1845, vol. I: 342).

Finalmente, esta obra traducida se consideró altamente subversiva y se vio la conveniencia de no publicarla en Cuba, ya que hubiese podido provocar la rebelión de los esclavos negros. Así, pues, vemos que el contexto histórico-social puede, por un lado, favorecer la traducción y, por otro lado, arrinconarla.

Los acontecimientos que ha habido en este país acerca de los negros, hacen peligrosa toda publicación sobre la materia en la isla de Cuba mucho más cuando Inglaterra ha declarado la libertad de sus esclavos. Por consiguiente, una obra en que no sólo se ataca la esclavitud, sino que se presentan los derechos del hombre en toda su extensión, y se hace ver que corresponden a la raza de color no menos que a la blanca [...] en relación a sus traductores, estos no van a chocar con una clase sola de la sociedad cubana, sino contra todas, pues la familia más pobre posee uno o dos esclavos. Se esparcirá la voz de que se ha publicado una obra para levantar a los negros, y sin leerla, empezarán a maldecir a sus autores (Del Monte 1834, cit. en Del Monte 1822-1845, vol. I: 370)

Si bien el ejemplo traído aquí versa sobre las tertulias literarias en la Cuba decimonónica, estas tertulias desarrollan en Europa una dinámica actividad desde el siglo XVII, y en Italia ya durante el siglo XVI. Baste recordar las tertulias de eruditos organizadas por Vittoria Colonna, por ejemplo. Muchos de esos salones literarios estaban dirigidos por mujeres, tal y como detalla con acierto la autora y traductora Von der Heyden-Rynsch (1992) en una monografía dedicada a esta actividad social, cultural y literaria.

La idea general de que el estudiante adquiera gusto por la investigación y amplíe sus horizontes cognitivos se procura en este tema presentando el atractivo de los salones y tertulias literarias, incentivando el que localicen datos sobre una tertulia literaria concreta, como por ejemplo la tertulia del Café de Pombo o la tertulia del Café Gijón, y redacten una reseña sobre su funcionamiento, mencionen quiénes forman parte de la misma, si entre ellos hay también traductores, y si, asociada a la tertulia, existe una publicación especializada en la que se reseñen traducciones.

La relación de contextos a estudiar puede ampliar el abanico de posibilidades hacia muchos campos de la actividad humana relacionados con la traducción y en diferentes épocas. Así, por ejemplo, en el contexto históricoeconómico también podemos analizar la traducción en la España del siglo XVI, como sería el caso de que el autor concreto a estudiar fuese fray Luis de León y su traducción del Cantar de los Cantares. El marco económico, 
y también el académico, en el que podemos situar el estudio del autor y su traslación, podría focalizarse en la floreciente industria de la edición de libros en la Salamanca renacentista y universitaria, gracias al asentamiento en la Península de grandes familias de dinámicos impresores extranjeros, como Juan Pulman y otros muchos, cuya aguda visión comercial contribuyó sin duda a extender el mercado de la traducción (Robben 1990: 53-61).

Por otro lado, en un contexto histórico-científico de un cronotopo determinado, lógicamente se puede estudiar la historia de la traducción en el campo de la medicina (García Bravo 2004: 25-42), de la farmacia (Van Hoof 1999: 27-44), etc. Las posibilidades, en fin, de escoger contenidos y didactizarlos para la formación humanística de los futuros traductores son múltiples y permiten la variedad temática y de contenido de un curso académico a otro, en función de la homogeneidad o heterogeneidad del grupo destinatario.

\section{Tercer escalón: Perfiles biográficos a través de la historia}

El siguiente escalón versa sobre los perfiles biográficos, no sólo de grandes figuras de la profesión, tal y como propone Delisle (2003: 230), sino también de aquellos que han buscado el anonimato, en muchas ocasiones, por motivos de seguridad o de aquellos otros cuya labor no es tan conocida, porque su tarea traductiva ha sido un complemento de su profesión, ligada directa o tangencialmente con la escritura, como pueda ser, por ejemplo, el caso del que fuera archivero de la Biblioteca Nacional Lorenzo González Agejas. No cabe duda de que los actores principales de la historia de la traducción son los traductores, sin cuya labor - bien a través del encargo por necesidades políticas, literarias, económicas, científicas, sociales, etc., mediante el mecenazgo por motivos de prestigio cultural, o bien de la propuesta y decisión personal de emprender una determinada traducción - no se podría construir el edificio histórico porque carecería de los pilares fundamentales para su sostenimiento y razón de ser. Arencibia (1995: 53), hablando desde la otra orilla, dice que:

La Historia es la Gran Relatora del quién, qué, cómo, cuándo, dónde y por qué de la raza humana y de su mundo. Para los traductores e intérpretes, retrazar las huellas que dejó su profesión en el tiempo, identificar a sus artífices y recorrer su reflexión en las distintas circunstancias de su desempeño es mucho más que un quehacer curioso, es medirse con uno de los más antiguos, representativos y sugerentes ejemplos de dedicación humana a la útil tarea de la comunicación a lo largo de los tiempos [...] en esta orilla, como en la otra, los traductores e intérpretes tuvieron igual tarea de transmitir y perpetuar la memoria histórica de ideas y acontecimientos [...] 
El historiador de la traducción Balliu (1995: 9) pone el acento en el papel protagonista del traductor en el devenir histórico, afirmando que: "El traductor, como cualquier otro protagonista de la vida social, pertenece a una época y a un entorno sociológico y cultural del que no sólo forma parte, sino con el que se compromete por su labor creadora".

Así, pues, en este escalón del proceso de enseñanza-aprendizaje, incitamos al alumno a la consulta bibliográfica focalizada en la localización de datos sobre traductores, ya se trate de diccionarios biográficos de diversos países, obras sobre traductores (Delisle y Woodsworth 1995, 2005), repertorios bibliográficos (Menéndez Pelayo 1876; Palau y Dulcet 1923-1945; Pellicer y Saforcada 1778), en obras sobre historia de la traducción (Santoyo 1999; Ruiz Casanova 2000; y otros), diccionarios históricos de la traducción (Lafarga y Pegenaute 2009), artículos en monografías (Corredor Plaja 2012), revistas especializadas, bases de datos, páginas de grupos de investigación en historia de la traducción, o también en actas de congresos sobre traducción.

A los estudiantes se les entrega, en primer lugar, una breve relación con una selección de nombres de traductores a lo largo de la historia y se les pide como tarea que traten de responder a las preguntas de ¿quién traducía?, ¿dónde?, ¿por qué traducía?, ¿para quién?, ¿qué traducía? Y, en segundo lugar, se les solicita que consulten en la página de la Biblioteca Virtual Miguel de Cervantes algunos de los textos traducidos por dichos traductores o bien por otros que estén más en la línea de sus intereses culturales. El objetivo principal es que, una vez leído el texto, respondan también a la pregunta de cómo traducía un determinado traductor e iniciarse así en la crítica de traducción; crítica que es preceptivo entregar por escrito, tras el debate organizado en el aula. En la puesta en común de estas críticas de traducción realizadas por los discentes, se les hace ver la estrecha relación entre la historia y la teoría de la traducción, y cómo las decisiones tomadas por el traductor al verter un texto pueden enlazarse con el contexto en que se desarrollan y con el tipo de texto. Al llegar a este punto, y en caso de que el discente haya aprovechado al máximo el desarrollo del curso, estará mejor preparado para el análisis de fragmentos de textos sobre teoría de la traducción, sobre las reflexiones en torno a la actividad traductora que los traductores han plasmado por escrito a lo largo de la historia.

Para la obtención de material de trabajo se acude también a artículos concretos sobre determinados traductores y que sean de fácil acceso para el alumnado, bien porque estén digitalizados o bien porque se cuente con una biblioteca bien dotada de bibliografía especializada, con el fin de allanar el camino para completar la tarea encomendada sobre los perfiles biográficos 
de algunos traductores. Autores como Vega Cernuda (1995a, 1995b, 19961997b, 2005-2006), Martínez Manzano (1995), Guzmán Guerra (1995) y Coriasso (2005-2006), entre otros, además de grupos de investigación como HISTRAD, tienen en su producción investigadora y bibliográfica interesantes artículos, más o menos extensos sobre la vida, traductografía y reflexiones en torno a la traducción por parte de traductores que, de una u otra manera, han dejado huella en la historia de la traducción. Esta tarea contribuye a que el alumnado se conciencie de la importancia y la relevancia de la profesión en la historia de la cultura, al tiempo que amplía sus conocimientos sobre la recepción de obras y autores a través de la traducción.

\section{Cuarto escalón: Análisis, debate y comentario de textos}

En este apartado son tres las obras básicas sobre las que se fundamenta el proceso de análisis, debate y comentario de textos: Textos clásicos de teoría de la traducción (Vega Cernuda 1994), Aproximación a una historia de la traducción en España (Ruíz Casanova 2000) y Sobre la traducción: textos clásicos y medievales (Santoyo Mediavilla 2011).

Cuando el docente inicia el cuarto y último escalón en el proceso de enseñanza-aprendizaje de historia de la traducción, los estudiantes han recibido información y formación partiendo de imágenes representativas de hitos en la historia de la traducción, pasando por el conocimiento de los contextos y sus textos, abordando posteriormente biografías de traductores y su obra. Llegados a este punto, el alumno está más capacitado para observar y repensar las reflexiones en torno a la traducción expresadas por los propios traductores a lo largo de la historia. Es el momento de traer a la luz las reflexiones de Cicerón, de san Jerónimo, de Boecio, Maimónides, Roger Bacon, Leonardo Bruni, Alonso de Madrigal, Lutero, Juan Luis Vives, Étienne Dolet, fray Luis de León, Dryden, Alexander Pope, Breitinger, D'Alembert, August Wilhelm Schlegel, Schleiermacher, Walter Benjamin, Rudolf Pannwitz, Svetlana Geier, y de tantos otros, unos de gran relevancia histórica y otros con una repercusión menor, debido quizá al ámbito de recepción circunscrito a un determinado grupo humano, pero que también han aportado su pequeño granito de arena a la reflexión traductiva y traductológica a través de prólogos y prefacios. Un artículo de reciente publicación (Schrader-Kniffki 2012) saca a la luz interesantes reflexiones de varios traductores literarios, entrevistados por la autora del artículo, en torno al significado que para ellos tiene la traducción, cómo se inspiran, cuáles son sus cuitas durante el proceso traductor, poniendo al traductor como centro epistémico de la traducción. 
Los fragmentos de textos a analizar, debatir y comentar se acompañan de una idea que pueda dar pie a orientar el análisis. A título de ejemplo, mencionamos tan sólo cinco fragmentos, si bien, al igual que en el resto de los escalones de nuestra propuesta, el contenido es intercambiable o ampliable:

1. Marco Tulio Cicerón (106-43 a.C.) El orador perfecto (46 a.C.) (en Vega 1994: 77): "Sobre la utilidad de la literatura clásica en la formación del traductor"

[...] Pero como se comete un gran error al definir esta especie de estilo (ático), he creído que tenía que emprender un trabajo útil para los estudiosos, aunque a mí mismo no me fuera en absoluto necesario. Y por eso traduje los dos discursos más célebres de los dos oradores áticos más elocuentes, dos discursos que se oponían entre sí: uno de Esquines y otro de Demóstenes. Y no lo traduje como intérprete, sino como orador, con la misma presentación de las ideas y de las figuras, si bien adaptando las palabras a nuestras costumbres. En los cuales no me fue preciso traducir palabra por palabra, sino que conservé el género entero de las palabras y la fuerza de las mismas. No consideré oportuno el dárselas al lector en su número, sino en su peso. Este trabajo tiene por objeto que nuestras gentes comprendan aquello que tienen derecho a exigir de aquellos que se pretenden áticos y a qué tipo de estilo deben ellos referirse [...]

2. San Jerónimo (ca.347-520 d.C.), Prólogo a los Libros de Salomón, traducidos del hebreo (en Martino 2007: 459): "Sobre la belleza de los rasgos estilísticos" y "Sobre la actualización".

[...] Si hay alguien a quien, con razón, le agrada más la edición de los Setenta Intérpretes, la tiene enmendada antaño por nosotros, pues no construimos cosas nuevas de manera que destruyamos las antiguas. Y, sin embargo, cuando los haya leído con mucha atención, advertirá que se entienden mejor los nuestros, que no se acumulan y corrompen trasegados a una tercera vasija, sino que desde la prensa misma vertidos en una limpísima tinaja han conservado su genuino sabor $[\ldots]$

3. Maimónides (1135-1204), Carta a Ben Tibbon (1199) (en Vega 1994: 87): "Sobre las equivalencias" y "Sobre las tendencias deformantes".

[...] Y siempre que traduzcas de una lengua a otra, hazlo conforme a la inteligencia que Dios, alabado sea, te ha dado para que comprendas las metáforas, las alegorías y las palabras de los sabios y sus enigmas $[\ldots]$ El traductor debe, sobre todo, aclarar el desarrollo del pensamiento, después escribirlo, comentarlo y explicarlo de modo que el mismo pensamiento sea claro y comprensible en la otra lengua. Y esto sólo se puede conseguir cambiando a veces lo que le precede y 
le sigue, traduciendo un solo término por más palabras y varias palabras por una sola, dejando aparte algunas expresiones y juntando otras, hasta que el desarrollo del pensamiento esté perfectamente claro y ordenado y la misma expresión se haga comprensible, como si fuera típica de la lengua a la que se traduce [...]

4. Fray Vicente Solano Machuca (1781-1865) La Guerra Catilinaria (pp. 142-143): "Sobre la función de la traducción"

[...] Es muy dificultoso verter un escrito en otra lengua; por manera que según el sentir de varios críticos juiciosos, es más fácil escribir una buena obra, que traducir con acierto. Comúnmente oímos decir: fulano sabe traducir el inglés, el francés, el latín, etc., como si la traducción fuera el trabajo más fácil de cuantos se conocen. A más del conocimiento de los idiomas, traducir es hacer hablar á un muerto, ó al que se halla ausente, en un lenguaje en que no han hablado: es penetrar sus ideas, ponerse en lugar de ellos, y supuren otra lengua lo que tal vez el idioma del original no alcanzó á expresar. En una palabra, es el último esfuerzo del ingenio humano: un don particular que la naturaleza nos distribuye con profusión [...] Mi intención ha sido expresar del modo posible los pensamientos del autor para hacer una obra popular, y no una clásica de literatura. Por esto he omitido tantas notas filológicas, que traen los traductores y comentadores de Salustio; y sólo me he contentado con poner algunas que tengan relación con la moral y la política, que son el objeto de la presente traducción.

5. Marcelino Menéndez Pelayo (1856-1912). Prólogo a los Poemas de Heine (1883) (en Vega 1994: 268): "Sobre la traducción de poesía"

[...] Es condición de la belleza eminente no ser de la que los filólogos guardan para fruición suya, ni de la que se pierde por adjetivo de más o de menos, sino de la que resiste a todas las manos que la trabajan y reproducen, y por ser su raíz universal y humana, es también comunicable y difusa en alto grado y es a un mismo tiempo la más traducible y la más intraducible de todas las creaciones del arte. No se traduce el sonido de las palabras, pero se traduce su vibración en el alma, que es lo que importa. Lo demás, fácilmente lo adivinará quienquiera que tenga sentido poético [...]

Las horas dedicadas por los estudiantes de historia de la traducción a esta tarea lectora y reflexiva llevan aparejados el debate sobre las ideas contenidas o sugeridas en los textos, así como comentarios de tipo formal y estilístico, búsqueda de datos biográficos sobre autores-traductores y una reseña sobre una obra traductológica escrita por un traductor.

Este bloque de contenidos finaliza con la ampliación de consultas en antologías de textos, ya por cuenta de cada alumno y no como tarea dirigida, 
con el objetivo de que busquen lo escrito por otros traductores y se les pide que aporten tres fichas con su valoración personal sobre las ideas expresadas en dichos textos y traten de rebatirlas, si no están de acuerdo con ellas, fundamentando sus argumentos. Además de ello, se incentiva nuevamente la consulta en repertorios bibliográficos, bases de datos, en el Diccionario histórico de la traducción en España, en revistas de historia de la traducción o especializadas en traducción, pero en las que se conceda una especial relevancia a los artículos relacionados con la historia de la traducción, etc. para completar su argumentación. La actividad hace que el alumno sea también consciente del número de traducciones que pueda tener una determinada obra, o cuántas obras de un autor han sido trasladadas a otras lenguas, etc., lo que contribuye a que aprecien el valor que tiene la actividad del traductor.

\section{Quinto escalón: Conclusiones}

La estructura planteada permite al docente modificar los contenidos, pero manteniendo unos puntos de apoyo referenciales. Así, pues, se pueden variar de un curso a otro las imágenes iniciales para presentar la panorámica general de la historia de la traducción e interpretación, las tareas a realizar por los estudiantes, los textos a analizar y debatir, los traductores elegidos para destacar los perfiles biográficos y su obra traductográfica, etc. Ello permite también al docente una ampliación de horizontes mentales y dinamismo en el ejercicio de la docencia y estar constantemente al día, ya que en función de novedosas investigaciones y publicaciones recientes puede ir escogiendo nuevo material de trabajo y adaptar el contenido, didactizándolo, a las necesidades de cada curso académico. Cuanto mayor es el poso cultural del docente, mayor será el aprovechamiento formativo por parte del discente.

La opción del intercambio de opiniones, del planteamiento de ideas sugeridoras al hilo de las imágenes, y el consiguiente debate permiten no sólo la reflexión sobre la actividad de los traductores a lo largo de la historia, sino también un mejor asentamiento de nuevos conocimientos sobre la base de lo ya conocido, recordado o sabido. Consideramos que nuestra propuesta de didactización de contenidos permite una progresión aritmética en el proceso de enseñanza y una progresión geométrica en el proceso de aprendizaje.

El conjunto de tareas que se realizan en cada una de las cuatro partes o escalones de la asignatura, y que se han ido especificando en los correspondientes aparados, se valora con veinticinco puntos, siendo necesario obtener un mínimo de trece puntos en cada escalón para que la evaluación por tareas sea superada con éxito. La nota final es el resultado de sumar la puntuación obtenida en cada uno de los cuatro apartados propuestos. 
El planteamiento que, a priori, parece excesivamente abarcador es en realidad una suma de pinceladas que comienzan con un boceto y pretenden, al acabar el lienzo, fomentar la reflexión y el debate sobre los pasos dados, pero también la lectura y la escritura. Por un lado, la reflexión sobre los textos leídos porque favorece la comprensión, tal y como decía Cicerón en El orador (2008: 29-49):

[...] yo sostengo que en ningún género hay nada tan hermoso que no sea superado por aquello de donde se saca, como se saca un retrato, por así decir, de un rostro; eso no puede ser percibido por los ojos, ni por los oídos, ni por ningún sentido; sólo lo comprendemos con el pensamiento y la mente [...] no hay nada más fértil que la mente, sobre todo la mente cultivada en los estudios.

Por otro lado, impulsar la práctica de la escritura. El fruto de la mucha lectura debe ser la escritura, tal y como el papa Dámaso le dijo a san Jerónimo, quien trabajó en calidad de secretario de lenguas entre los años 382 y 384 en Roma antes de dedicarse plenamente a la traducción de los textos bíblicos. Esta recomendación del mucho leer y después escribir sería deseable transmitírsela también a nuestros alumnos, ya que la actividad redactora contribuye a mejorar con el tiempo el estilo y la capacidad expresiva y de reescritura.

\section{Referencias bibliográficas}

ARENCIBIA ROdRíGUEZ, Lourdes. (1995) "La traducción: Mare Nostrum muchos siglos después." Hieronymus Complutensis 1, pp. 53-61.

ARENCIBIA RODRÍGUEZ, Lourdes. (1996-1997) "La traducción en las tertulias literarias del siglo XIX en Cuba." Hieronymus Complutensis 4-5, pp. 27-40.

Balliu, Christian. (1995) "Los traductores transparentes. Historia de la traducción en Francia durante el periodo clásico." Hieronymus Complutensis 1, pp. 9-51.

CANTERA ORTiz DE URBina, Jesús. (1995) "Antiguas versiones bíblicas y traducción." Hieronymus Complutensis 2, pp. 53-60.

CANTERA Ortiz de URBina, Jesús. (1996-1997) "La traducción de la Biblia. Enfoque filológico y enfoque pastoral." Hieronymus Complutensis 4-5, pp. 101-117.

CANTERA ORTIZ DE URBINA, Jesús. (1999) "Cultura religiosa (cristianismo, judaísmo e islamismo) y traducción." Hieronymus Complutensis 8, pp. 107-124.

CiCERón. (46 a.C.) El orador. Citado por la edición y traducción de Eustaquio Sánchez Salor. (2008) Madrid: Alianza Editorial.

CORIASSO, Cristina. (2005-2006) "Leopardi traductor y traductólogo." Hieronymus Complutensis 11, pp. 79-85.

Corredor Plaja, Anna-María. (2012) "Presencia de la traducción en las novedades bibliográficas de La Ilustración Española y Americana (1869-1889).” En: 
Martino Alba, Pilar \& Salud M. Jarilla (eds.) (2012) Caleidoscopio de traducción literaria. Madrid: Ed. Dykinson, pp.25-43.

De Bernardo AREs, José Manuel; Elena Echeverría Pereda \& Emilio Ortega Arjonilla. (2011) De Madrid a Versalles. Madrid: Ariel.

Del Monte, Domingo. (1822-1845) Centón Epistolario. La Habana: Ediciones Imagen Contemporánea, vol. I, 2002. Versión electrónica: <http: //bdigital. bnjm.cu/secciones/literatura/autores/80/obras/montel_todo.pdf>

Delisle, Jean. (1995) Les traducteurs dans l'histoire. Presses de l'Université d'Ottawa. Citado por la traducción española de Martha Pulido et. al. (2005). Los traductores en la historia. Medellín: Universidad de Antioquia.

DelisLe, Jean. (2003) "La historia de la traducción: su importancia para la traductología y su enseñanza mediante un programa didáctico multimedia y multilingüe." Citado por la traducción española de Anna Maria Salvetti. Ikala: revista de lenguaje y cultura 8: 14, pp. 221-235.

Fernández SÁnchez, María Manuela y José Antonio Sabio Pinilla. (1999) "Traducción clásica y reflexiones sobre la traducción en la Corte de Aviz." Hieronymus Complutensis 8, pp. 61-72.

Fuhrmann, Manfred. (1992) Die Dichtungstheorie der Antike. Aristoteles, Horaz, 'Longin'. Darmstadt: Wissenschaftliche Buchgesellschaft. Citado por la traducción de Alfonso Silván: La teoría poética de la Antigüedad. Aristóteles-Horacio-Longino. Madrid: Dykinson, 2011.

García Bravo, Paloma. (2004) "Las traducciones en la transmisión del legado médico clásico en el mundo occidental." Hieronymus Complutensis 11, pp. $25-42$.

GARCÍA De CoRTÁZAR, Fernando. (2007) Historia de España a través del arte. Barcelona: Planeta.

GUZMÁN GUERRA, Antonio. (1995) "Leonardo Bruni: traductor y traductólogo del Humanismo." Hieronymus Complutensis 2, pp. 75-80.

Herodoto. (siglo V a. C.) Historia [traducido por José M. Floristán Madrid: Dykinson, 2010].

JURETSCHKE, Hans. (2001) España y Europa. Estudios de crítica cultural. 3 tomos, editor: Miguel Ángel Vega Cernuda, Madrid: Universidad Complutense de Madrid.

Lafarga, Francisco y Luis Pegenaute (eds.) (2004) Historia de la traducción en España. Salamanca: Ediciones Ambos Mundos.

Lafarga, Francisco y Luis Pegenaute (eds.) (2009) Diccionario histórico de la traducción en España, Madrid: Gredos.

Lafarga, Francisco; Concepción Palacios y Alfonso Saura (eds.) (2002) Neoclásicos y románticos ante la traducción. Murcia: Universidad de Murcia.

Martínez Manzano, Teresa. (1995) "Las retraducciones al griego clásico de Constantino Láscaris." Hieronymus Complutensis 2, pp. 9-27. 
Martino Alba, Pilar. (2007) "San Jerónimo: traductor y traductólogo." En: Navarro Domínguez, Fernando; Miguel Ángel Vega Cernuda; Juan Antonio Albaladejo Martínez; Daniel Gallego Hernández y Miguel Tolosa Igualada (eds.) 2007. La traducción: balance del pasado y retos del futuro, Alicante: Universidad de Alicante / Dpto. de Traducción y Editorial Aguaclara, pp. 453-466.

MenÉndez Pelayo, Marcelino. (1876) Biblioteca de traductores españoles, Madrid: Fundación Mapfre, DIGIBÍS, 2009. Versión electrónica: <http: //www.larramendi.es/i18n/corpus/unidad.cmd? idCorpus $=1000 \&$ idUnidad $=101005 \&$ po sicion $=1>$

PAJARES INFANTE, Eterio. (2010) La traducción de la novela inglesa del siglo XVIII. Vitoria: Portal Editions.

Palau y Dulcet, Antonio. (1923-1945). Manual del librero hispano-americano: inventario bibliográfico de la producción científica y literaria de España y de la América Latina desde la invención de la imprenta hasta nuestros días, con el valor comercial de todos los artículos descritos. 1948-1987, 35 vols. (segunda edición), Barcelona: Librería Antiquaria.

Pellicer y SAFORCADA, Juan Antonio. (1778). Ensayo de una bibliotheca de traductores españoles. Madrid: Antonio Sancha. Versión electrónica en edición facsímil: <http: //www.traduccionliteraria.org/biblib/misc/MS101.htm>

RobBEn, F.M.A. (1990) "Juan Pulman, librero y agente de la oficina plantianiana en Salamanca (1579-ca.1609), un avance.” En: Tromp, Hans \& Pedro Pereira (eds.) 1990. Simposio internacional sobre Cristóbal Plantino. Madrid: Universidad Complutense de Madrid.

Ruiz Casanova, José Francisco. (2000) Aproximación a una historia de la traducción en España. Madrid: Cátedra.

Santoyo Mediavilla, Julio César. (2011) Sobre la traducción: textos clásicos y medievales. León: Universidad de León.

Santoyo Mediavilla, Julio César. (1995) Historia de la traducción. Quince apuntes. León: Universidad de León.

SCHRADER-KNIFFKI, Martina. (2012) "Percepción y concepto de lengua en procesos de traducción: Aproximaciones lingüísticas a una teoría de la traducción basada en entrevistas con traductores." En: Martino Alba, Pilar y Christiane Lebsanft (eds.) 2012. Telar de traducción especializada. Madrid: Dykinson, pp. 11-24.

Solano MachuCA, Vicente Fr. (1851) La Guerra Catilinaria. Cuenca: Impr. de la Vda. de Muñoz. Versión electrónica: <http: //web.ua.es/es/histrad/documentos/biografias/fray-vicente-solano.pdf>

SteInER, George. (1975) After Babel. Aspects of Language and Translation. Oxford: Oxford University Press. Citado por la traducción de Adolfo Castañón y Aurelio Major: Después de Babel. Madrid, FCE, 1995. 
Tobar, María Luisa. (2012) "La traducción de autor: Elio Vittorini, traductor de obras teatrales españolas." En: Martino Alba, Pilar (2012) La traducción en las artes escénicas. Madrid: Dykinson, pp. 111-125.

VAN HoOF, Henri. (1996-1997) "Le traducteur, auteur de dictionnaires." Hieronymus Complutensis 4-5, pp.17-26.

VAN Hoof, Henri. (1999) "Notes pour une histoire de la traduction pharmaceutique." Hieronymus Complutensis 8, pp. 27-44.

Vega Cennuda, Miguel Ángel. (1994) Textos clásicos de teoría de la traducción. Madrid: Cátedra.

Vega Cernuda, Miguel Ángel. (1995a) "La lingüística de un pensador de la economía o la poética (traductiva) de Adam Smith." Hieronymus Complutensis 1, pp. 87-92.

Vega Cernuda, Miguel Ángel. (1995b) "Las teorías translatorias del Abbé Desfontaines." Hieronymus Complutensis 2, pp. 67-73.

VeGa CERnUdA, Miguel Ángel. (1996-1997a) "Apuntes socioculturales de historia de la traducción: del Renacimiento a nuestros días." Hieronymus Complutensis 4-5, pp. 71-85.

Vega Cernuda, Miguel Ángel. (1996-1997b) "Entrevista a Paco Uriz." Hieronymus Complutensis 4-5, pp. 157.

Vega Cernuda, Miguel Ángel (ed.) (2001) España y Europa. Estudios de critica cultural. Obras completas de Hans Juretschke, t.I, t.II, t.III. Madrid: Ed. Complutense.

Vega Cernuda, Miguel Ángel. (2002-2003) "Una mirada retrospectiva y escéptica a la teoría de la traducción." Hieronymus Complutensis 9-10, pp. 63-76.

Vega Cernuda, Miguel Ángel. (2004) "Lenguas, farautes y traductores en el encuentro de los mundos. Apuntes para una historia de la comunicación lingüística en la época de los descubrimientos en la América protohispana." Hieronymus Complutensis 11, pp. 81-108.

Vega Cernuda, Miguel Ángel. (2005-2006) "Rilke y la traducción." Hieronymus Complutensis 11, pp. 7-11.

VON DER HEYDEN-RYNSCH, Verena. (1992) Europäische Salons. Höhepunkte einer versunkenen weiblichen Kultur. München: Artemis \& Winkler. Citado por la traducción de José Luis Gil Aristu: Los salones europeos: las cimas de una cultura femenina desaparecida. Madrid: Península, 1998. 


\section{NOTA BIOGRÁFICA / BIONOTE}

Doctora en Historia del Arte por la Universidad Complutense; DEA en Traducción por la Universidad de Alicante; Máster universitario en Traducción por la Universidad de Sevilla; Diplomada en Empresas y Actividades Turísticas. Es Profesora Titular de Universidad en el Departamento de Filología I de la Universidad Rey Juan Carlos (Madrid) y profesora colaboradora del Instituto Universitario de Lenguas Modernas y Traductores. Sus líneas de investigación se centran en el mundo del arte y el de la traducción. Investiga sobre temas iconográficos y su relación con las fuentes escritas, y sobre la relación entre autorretrato y autobiografía, y su traducción. Profesora visitante en Lima, Münster, Magdeburg y Wilhelmshaven. Ejerce la traducción y ha publicado una cincuentena de artículos relacionados con sus líneas principales de investigación y, en calidad de editora, tres monografías de investigación en traducción. Es miembro del grupo de investigación en traducción HISTRAD y del grupo LAMICRE (arte y comunicación).

PhD in Art History from Universidad Complutense; Diploma on Advanced Studies in Translation from the University of Alicante; Master's degree in Translation German-Spanish from the University of Seville; Diploma in Business and Touristic Activities. She is Senior Lecturer at the Department of Philology of the Universidad Rey Juan Carlos (Madrid), and collaborates since 1998 with the Institute of Modern Languages and Translators. Her research lines are focused on Art and Translation. She researches on iconographic themes and their relationship with written sources, as well as on the relationship between self-portrait and autobiography, and its translation into different languages. Visiting Lecturer in Lima, Münster, Magdeburg and Wilhelmshaven. She has published about fifty articles relating to her main lines of research, she has edited three monographs of research in translation and has translated various books. She is a member of the group of research in translation HISTRAD and also member of LAMICRE (art and communication research group). 